\title{
Amyloid- $\beta$ Peptide Oligomers Disrupt Axonal Transport through an NMDA Receptor-Dependent Mechanism That Is Mediated by Glycogen Synthase Kinase $3 \beta$ in Primary Cultured Hippocampal Neurons
}

\author{
Helena Decker, ${ }^{1,2,3}$ Karen Y. Lo, ${ }^{1}$ Sandra M. Unger, ${ }^{1}$ Sergio T. Ferreira, ${ }^{2}$ and Michael A. Silverman ${ }^{1}$ \\ ${ }^{1}$ Department of Biological Sciences, Simon Fraser University, Burnaby, British Columbia V5A 1S6, Canada, and ${ }^{2}$ Institute of Medical Biochemistry and \\ ${ }^{3}$ Morphological Sciences Program, Institute of Biomedical Sciences, Federal University of Rio de Janeiro, Rio de Janeiro, RJ 21944-590, Brazil
}

\begin{abstract}
Disruption of axonal transport is a hallmark of several neurodegenerative diseases, including Alzheimer's disease (AD). Even though defective transport is considered an early pathologic event, the mechanisms by which neurodegenerative insults impact transport are poorly understood. We show that soluble oligomers of the amyloid- $\beta$ peptide (A $\beta 0$ s), increasingly recognized as the proximal neurotoxins in $\mathrm{AD}$ pathology, induce disruption of organelle transport in primary hippocampal neurons in culture. Live imaging of fluorescent protein-tagged organelles revealed a marked decrease in axonal trafficking of dense-core vesicles and mitochondria in the presence of 0.5 $\mu \mathrm{M} A \beta 0$ s. NMDA receptor (NMDAR) antagonists, including D-AP5, MK-801, and memantine, prevented the disruption of trafficking, thereby identifying signals for A $\beta 0$ action at the cell membrane. Significantly, both pharmacological inhibition of glycogen synthase kinase- $3 \beta$ (GSK-3 $\beta$ ) and transfection of neurons with a kinase-dead form of GSK-3 $\beta$ prevented the transport defect. Finally, we demonstrate by biochemical and immunocytochemical means that $\mathrm{A} \beta 0$ s do not affect microtubule stability, indicating that disruption of transport involves a more subtle mechanism than microtubule destabilization, likely the dysregulation of intracellular signaling cascades. Results demonstrate that $\mathrm{A} \beta 0$ s negatively impact axonal transport by a mechanism that is initiated by NMDARs and mediated by GSK- $3 \beta$ and establish a new connection between toxic $\mathrm{A} \beta$ oligomers and $\mathrm{AD}$ pathology.
\end{abstract}

\section{Introduction}

Fast axonal transport (FAT) is crucial for neuronal function and survival. Because the axon is mostly devoid of biosynthetic machinery, proteins, lipids, and organelles are transported long distances from the cell body, and trophic factors secreted from axonal targets are transported retrogradely from the synapse to the cell body. Multiple neurodegenerative diseases, including Alzheimer's disease (AD), Huntington's disease, and amyotrophic lateral sclerosis display defective FAT as an early pathologic event (Morfini et al., 2009). In particular, axonal transport defects have been found in $\mathrm{AD}$ brain (Stokin et al., 2005; Muresan and Muresan, 2009) and in transgenic mouse models of AD (Muresan and Muresan, 2009).

Soluble oligomers of the amyloid- $\beta$ peptide $(\mathrm{A} \beta \mathrm{Os})$ [also known as amyloid $\beta$-derived diffusible ligands (ADDLs)] are

\footnotetext{
Received March 2, 2010; revised May 5, 2010; accepted May 17, 2010.

This research was supported by grants from the National Science and Engineering Research Council (327100-06), the Canadian Foundation for Innovation (12793), and the Canadian Institutes of Health Research (90396) (to M.A.S.). S.T.F. is supported by grants from Conselho Nacional de Desenvolvimento Científico e Tecnológico, Fundação de Amparo à Pesquisa do Estado do Rio de Janeiro, and Instituto Nacional de Neurociência Translacional (Brazil). We thank Cheng Fang (Oregon Health \& Science University) for the $p \beta$-actin-BDNF-mRFP plasmid and H. Hutter and V. Gelfand for critical reading of this manuscript. H.D. thanks the Brazilian agency Coordenação de Aperfeiçoamento de Pessoal de Nível Superior for fellowship support.

Correspondence should be addressed to Michael A. Silverman, Department of Biological Sciences, Simon Fraser University, 8888 University Drive, Burnaby, BC V5A 156, Canada. E-mail: masilver@sfu.ca.

DOI:10.1523/JNEUROSCI.1074-10.2010

Copyright $\odot 2010$ the authors $\quad 0270-6474 / 10 / 309166-06 \$ 15.00 / 0$
}

neurotoxins that accumulate in the brains and CSF of AD patients and $\mathrm{AD}$ mouse models, acting as gain-of-function pathogenic ligands that attack synapses and block LTP in experimental models (Walsh et al., 2002; Wang et al., 2002; Klein, 2006). An increasing body of evidence indicates that $\mathrm{A} \beta \mathrm{Os}$, which are distinct from $\mathrm{A} \beta$ fibrils and monomers, are the proximal neurotoxins responsible for synapse failure and the early manifestations of AD pathology (Klein, 2006; Ferreira et al., 2007). Although A $\beta$ monomers and fibrils have been shown to interfere with transport (Hiruma et al., 2003; Rui et al., 2006) or when oligomeric A $\beta$ is applied to isolated squid axoplasm (Pigino et al., 2009), a role of pathogenic $\mathrm{A} \beta \mathrm{O}$ s in disruption of FAT has not been demonstrated in mammalian neurons.

$\mathrm{A} \beta \mathrm{O}$ s interfere with NMDA receptor (NMDAR) function, inducing abnormal calcium influx and neuronal oxidative stress (De Felice et al., 2007) and instigate aberrant activation of kinases, including glycogen synthase kinase- $3 \beta$ (GSK-3 $\beta$ ) (Hoshi et al., 2003; De Felice et al., 2008). Of direct relevance to the present study, GSK-3 $\beta$ impairs kinesin-1-based transport in squid axoplasm (Morfini et al., 2002).

Here, we demonstrate that $\mathrm{A} \beta \mathrm{O}$ s cause severe axonal transport defects in cultured hippocampal neurons by the direct imaging of actively transporting fluorescently tagged BDNFcontaining secretory vesicles and mitochondria. This impact on FAT is prevented by NMDAR antagonists, including memantine, and by inhibition of GSK-3 $\beta$ by pharmacological or molecular 


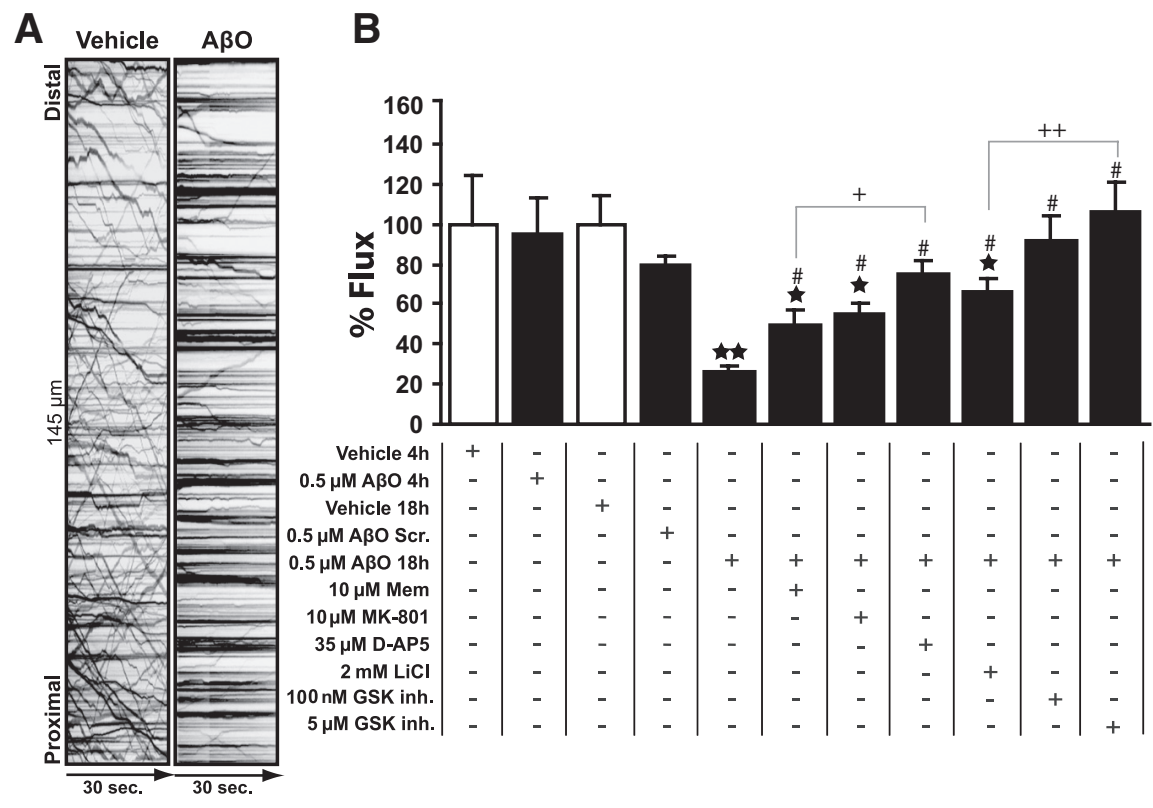

Figure 1. $A \beta 0$ s block organelle flux in hippocampal neurons. $A$, Representative kymographs comparing axonal DCV transport in control (vehicle) and $A \beta 0$-treated neurons ( $18 \mathrm{~h}, 0.5 \mu \mathrm{m} \mathrm{A} \beta 0 \mathrm{~s})$. Organelle flux is markedly reduced in the presence of $A \beta 0 \mathrm{~s}$ (right kymograph). $\boldsymbol{B}$, Effects of $A \beta 0$ s and other treatments on DCV flux. Disruption of transport can be partially prevented by memantine (Mem), MK-801, lithium, while full protection was obtained with D-AP5 and GSK-3 $\beta$ inhibitor VIII (GSK inh.). A minimum of 15 cells from at least 2 different cultures were analyzed per condition; ${ }^{* *} p<0.0001$ relative to vehicle-treated cultures, ${ }^{*} p$ ranging from 0.007 to 0.05 relative to vehicle-treated cultures in different experimental conditions. ${ }^{\#} p$ ranging from 0.0001 to 0.01 relative to $A \beta 0$-treated cultures in different experimental conditions. ${ }^{+} p<0.05$ comparing Mem $+A \beta 0$ s and $\mathrm{D}-\mathrm{AP} 5+\mathrm{A} \beta 0 \mathrm{~s} ;{ }^{++} p<0.005$ comparing A $\beta 0 \mathrm{~s}+\mathrm{LiCl}$ and A $\beta 0 \mathrm{~s}+$ GSK inh. $(5 \mu \mathrm{M})$. The first 4 bars are not significantly different between them $(p>0.05)$. Complete statistical evaluation is presented in supplemental Fig. S2, available at www. jneurosci.org as supplemental material.

tools. We also show that the integrity of the microtubule (MT) network and the protein levels of several microtubule-based motor proteins are unaffected by $\mathrm{A} \beta \mathrm{O}$ exposure. Our results establish that $\mathrm{A} \beta \mathrm{O}$ s instigate transport defects in mammalian neurons through a GSK-3 $\beta$-dependent mechanism that is independent of overt deleterious effects on the MT network.

\section{Materials and Methods}

Plasmids. $\mathrm{p} \beta$-actin-BDNF-mRFP was received from G. Banker (Oregon Health \& Science University, Portland, OR). Mitochondrially targeted YFP was received from G. Rintoul (Simon Fraser University, Burnaby, BC, Canada). pcDNA3 HA-GSK3 $\beta$ S9A pcDNA3, HA-GSK3 $\beta$ K85A (Addgene). Information about additional antibodies and reagents are in supplemental data, available at www.jneurosci.org as supplemental material.

Hippocampal cell cultures and expression of transgenes. Primary neurons were prepared as described previously (Kaech and Banker, 2006), and cultured in Neurobasal/B27 medium with antioxidants. Constructs were transfected into neurons at 9-12 d in vitro (DIV) using Lipofectamine 2000 (Invitrogen). Cells expressed constructs for $24 \mathrm{~h}$ before imaging.

$A \beta$ oligomer preparation. Soluble $\mathrm{A} \beta$ oligomers (ADDLs) were prepared by the method of De Felice et al. (2007). A $\beta$ Os $(0.5 \mu \mathrm{M})$ were added to cultures at the appropriate times ( 4 or $18 \mathrm{~h}$; see Results) before imaging.

Imaging. Cells were imaged live using a wide-field fluorescent microscope (DMI 6000 B, Leica) as described previously (Kwinter et al., 2009). Axons and dendrites were initially distinguished based on morphology and confirmed retrospectively by antibody staining against MAP-2, a dendritic cytoskeletal protein. Quantification of binding of $A \beta O$ s was done in 9-12 DIV neurons (supplemental Fig. S4, available at www. jneurosci.org as supplemental material).

Biochemical quantification of tubulin. Neurons were treated for $18 \mathrm{~h}$ with $0.5 \mu \mathrm{M}$ A $\beta$ Os. Cells were extracted with MT-stabilizing buffer I as described previously (Black et al., 1996). Equal volumes of Tritonsoluble and -insoluble fractions were then analyzed by immunoblotting with anti- $\alpha$-tubulin. Information about immunoblotting is in supplemental data, available at www.jneurosci.org as supplemental material.

Immunocytochemistry. Cells were fixed and stained as previously described (Kwinter et al., 2009). For saponin extractions, cells were washed with MT-stabilizing buffer II (Kempf et al., 1996).

Movies and quantitative analyses. Videos were processed using MetaMorph (Universal Imaging) as described previously (Kwinter et al., 2009). Quantitative analysis of immunofluorescence data was performed using ImageJ (De Felice et al., 2008). All values were compiled for analysis in Microsoft Excel and SPSS and significance difference between treatments was analyzed by $t$ test with equal or unequal variances at a $95 \%$ confidence interval.

\section{Results \\ Disruption of organelle trafficking by soluble $\mathrm{A} \beta \mathrm{O}$ s}

To determine whether $\mathrm{A} \beta \mathrm{O}$ s have an impact on fast axonal transport, hippocampal neuronal cultures expressing BDNF-mRFP, a dense-core vesicle (DCV) cargo, or mitochondrially targeted-YFP were live imaged 4 or $18 \mathrm{~h}$ after treatment with $0.5 \mu \mathrm{M} \mathrm{A} \beta O$ s. Representative kymographs of DCVs (Fig. $1 A$ ) and movies of DCV or mitochondria transport (supplemental Movie 1, available at www.jneurosci.org as supplemental material) readily demonstrate differences between organelle flux in control and $\mathrm{A} \beta \mathrm{O}$ treated neurons. Axonal fluxes of both DCVs (Fig. $1 B$ ) and mitochondria (supplemental Table 1, available at www.jneurosci. org as supplemental material) were dramatically decreased (by $\sim 76 \%$ and $\sim 74 \%$, respectively) after $18 \mathrm{~h}$ (but not after $4 \mathrm{~h}$ ) of exposure to $\mathrm{A} \beta \mathrm{O}$ s. Interestingly, $\mathrm{A} \beta \mathrm{O}$ s inhibited bidirectional organelle flux with a greater effect on anterograde DCV transport (supplemental Table 1, available at www.jneurosci.org as supplemental material). Additionally, we found significant reductions in average run-lengths of both DCVs and mitochondria (by $\sim 39 \%$ and $~ 56 \%$, respectively) and in average velocity of DCVs ( $\sim 21 \%)$ (supplemental Table 1, available at www.jneurosci.org as supplemental material). Importantly, and in line with previous reports (Deshpande et al., 2006; De Felice et al., 2007), during the time frame of our experiments $\mathrm{A} \beta \mathrm{O}$ s had no effect on cell viability assessed using propidium iodide staining (data not shown). In addition, cellular morphology after $18 \mathrm{~h}$ exposure to $\mathrm{A} \beta \mathrm{O}$ s was normal compared with controls; the axonal plasma membrane was intact, without any blebbing (supplemental Fig. S1 A, available at www.jneurosci.org as supplemental material), and the Golgi apparatus, a key component of the secretory pathway, exhibited normal stacked appearance in perinuclear and dendritic compartments (supplemental Fig. S1 B, available at www. jneurosci.org as supplemental material). These observations indicate that the effect of $\mathrm{A} \beta \mathrm{O}$ s on axonal transport did not result from gross changes in cell morphology and viability.

\section{Disruption of DCV transport is prevented by blocking NMDARs}

Pretreatment of neurons for 30 min with D-AP5 (35 $\mu \mathrm{M})$, a competitive NMDAR antagonist, completely prevented the transport defects induced by A $\beta$ Os (Fig. $1 B$; supplemental Table 1 , avail- 
able at www.jneurosci.org as supplemental material). To further investigate the role of NMDARs, the high affinity channel blocker MK-801 (5H-dibenzo[a,d]cyclohepten5,10-imine) $(10 \mu \mathrm{M})$ and a moderate affinity blocker, memantine $(10 \mu \mathrm{M})$, were used. Both compounds prevented transport defects induced by $\mathrm{A} \beta \mathrm{O}$, albeit to a lower extent than D-AP5 (Fig. $1 B$; supplemental Table 1, available at www. jneurosci.org as supplemental material). Interestingly, D-AP5, but not MK-801 or memantine, blocks $\mathrm{A} \beta \mathrm{O}$ binding to neurons (De Felice et al., 2007). Results thus suggest that aberrant activation of NMDARs by $\mathrm{A} \beta \mathrm{O}$ s plays a central role in initiating the disruption of FAT.

\section{Involvement of GSK- $3 \boldsymbol{\beta}$ signaling}

Several kinases are activated by $\mathrm{A} \beta \mathrm{Os}$, including GSK-3 $\beta$ (Hoshi et al., 2003; Ferreira et al., 2007). To explore whether GSK- $3 \beta$ plays a role in $\mathrm{A} \beta \mathrm{O}$-induced inhibition of FAT in primary neurons, cultures expressing BDNF-mRFP were pretreated for $30 \mathrm{~min}$ with GSK-3 $\beta$ inhibitor VIII (100 nM or $5 \mu \mathrm{M})$. GSK-3 $\beta$ inhibitor VIII completely prevented the transport defects induced by $\mathrm{A} \beta \mathrm{O}$ s (Fig. $1 B$; supplemental Table 1 , available at www.jneurosci.org as supplemental material) and $\mathrm{LiCl}(2 \mathrm{~mm})$, another GSK-3 $\beta$ inhibitor, yielded partial protection (Fig. $1 B$; supplemental Table 1 , available at www.jneurosci.org as supplemental material). Significantly, transfection of an inactive, kinase-dead form of GSK-3 $\beta$ (K85A) (Seo et al., 2008) fully blocked the transport defects in $\mathrm{A} \beta \mathrm{O}$-treated neurons (Fig. $2 B, C$ ). Conversely, transfection with a constitutively active form of GSK-3 $\beta$ (S9A) significantly inhibited DCV transport even in the absence of $\mathrm{A} \beta \mathrm{O}$ s (Fig. $2 B, C)$. These data provide strong support for a role of GSK-3 $\beta$ in the deleterious impact of $A \beta O$ s on FAT.

A $\beta O$ s do not induce MT destabilization $\mathrm{A} \beta \mathrm{O}$ s induce an increase in tau phosphorylation (De Felice et al., 2008), a modification that may alter cytoskeletal dynamics in neurons. Although a possible role of tau hyperphosphorylation in the disruption of FAT remains to be fully investigated, we have examined whether changes in the microtubule network might be a cause of the transport defects. To this end, MT stability was assessed through biochemical and immunocytochemical means. We found the equilibrium between polymerized and unpolymerized tubulin was unchanged in $\mathrm{A} \beta \mathrm{O}$-treated cells compared with controls (Fig. 3A). As a positive control for MT depolymerization, cells were treated with nocodazole, and the amount of soluble tubulin increased significantly (Fig. 3A). To further assess the integrity of the MT network, we evaluated the pres-

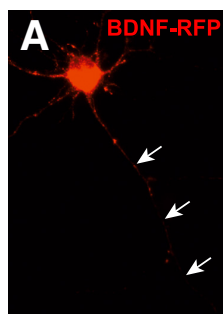

Flux $\left(\min ^{-1}\right)$

GSK-3 $\beta$ KA (S9A)

Velocity $(\mu \mathrm{m} / \mathrm{s})$

GSK-3 $\beta$ KA (S9A)

Run Length ( $\mu \mathrm{m})$

GSK-3 $\beta$ KA (S9A) (100\%). Scale bars, $25 \mu \mathrm{m}$.
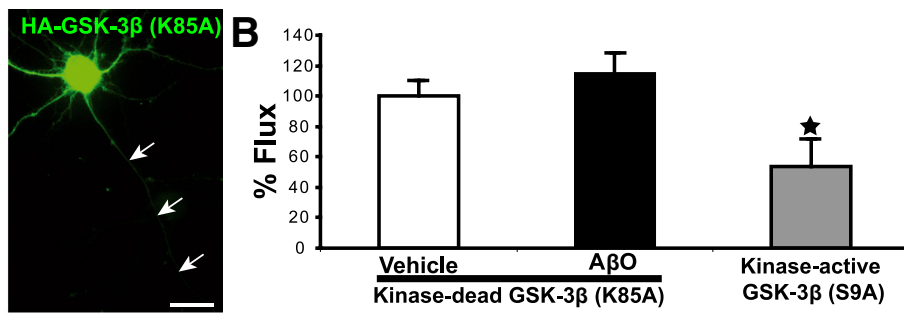

Vehicle - GSK-3 $\beta$ KD (K85A)

$A \beta O s$ - GSK-3 $\beta$ KD (K85A)

Vehicle - GSK-3 $\beta$ KD (K85A)

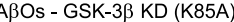

Vehicle - GSK-33 KD (K85A)

A 30 s - GSK-3 $\beta$ KD (K85A)

\begin{tabular}{|c|c|c|c|}
\hline \multicolumn{3}{|c|}{ Traffic Values } & $\%$ \\
\hline All events & Anterograde & Retrograde & All events \\
\hline $6.50 \pm 0.68$ & $2.79 \pm 0.51$ & $3.71 \pm 0.34$ & $100.00 \pm 10.44$ \\
\hline $7.43 \pm 0.91$ & $3.28 \pm 0.45$ & $4.15 \pm 0.57$ & $114.28 \pm 13.94$ \\
\hline $3.50 \pm 1.17$ & $1.59 \pm 0.58^{+}$ & $1.91 \pm 0.61^{* /+}$ & $53.83 \pm 17.98 * /+$ \\
\hline $1.91 \pm 0.08$ & $1.84 \pm 0.09$ & $1.96 \pm 0.08$ & $100.00 \pm 3.99$ \\
\hline $1.78 \pm 0.06$ & $1.69 \pm 0.07$ & $1.83 \pm 0.07$ & $93.17 \pm 2.90$ \\
\hline $1.35 \pm 0.10$ & $1.41 \pm 0.12^{* /+}$ & $1.22 \pm 0.13^{* * /++}$ & $70.45 \pm 5.10^{* * /+}$ \\
\hline $5.40 \pm 0.35$ & $5.32 \pm 0.43$ & $5.38 \pm 0.37$ & $100.00 \pm 6.48$ \\
\hline $4.97 \pm 0.15$ & $5.14 \pm 0.24$ & $5.86 \pm 0.16$ & $92.13 \pm 2.70$ \\
\hline $5.64 \pm 0.62$ & $6.54 \pm 1.17$ & $4.71 \pm 0.60$ & $104.52 \pm 11.52$ \\
\hline
\end{tabular}

Figure 2. Expression of kinase-dead GSK-3 $\beta$ (GSK-3 $\beta$ KD) (K85A) prevents $A \beta 0$-induced transport defects. $\boldsymbol{A}$, Expression of BDNF-RFP and HA-tagged GSK-3 $\beta$ KD in the same neuron; arrows indicate the axon. $\boldsymbol{B}$, Expression of GSK-3 $\beta$ KD in neurons prevents $A \beta 0$-induced transport defects. Conversely, expression of constitutively kinase-active GSK-3 $\beta$ (GSK-3 $\beta$ KA) (S9A) in the absence of $A \beta 0$ s disrupts $50 \%$ of DCV transport. Cells were fixed postimaging and stained with anti-HA to confirm the presence of GSK-3 $\beta$ (K85A or S9A). C, Summary of transport data. Vehicle/GSK-3 $\beta$ KD $n=12$ kymographs (12 cells, 1930 vesicles); $A \beta 0 /$ GSK-3 $\beta$ KD $n=19$ kymographs (19 cells, 3468 vesicles); GSK-3 $\beta$ KA $n=13$ kymographs (13 cells, 1320 vesicles). ${ }^{*} p<0.05$; ${ }^{* *} p<0.0001$, statistically significant difference compared with vehicle KD; ${ }^{+} p<0.05 ;{ }^{++} p<0.0001$, statistically significant difference compared with $A \beta 0$ KD. Scale bar, $25 \mu \mathrm{m}$.
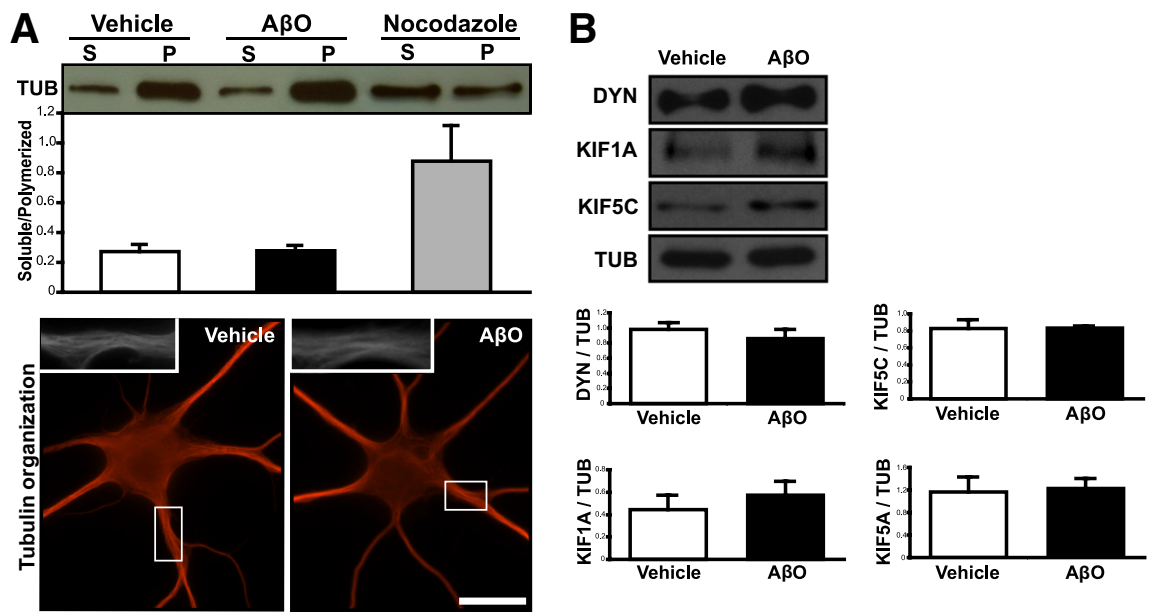

Figure 3. Neuronal cytoskeleton integrity is unaffected by $A \beta 0$ treatment. $\boldsymbol{A}$, Top, Immunoblots of tubulin from neurons extracted in MT buffer I. The ratio of soluble (S) to polymerized (P) tubulin in vehicle- and A $\beta 0$-treated cells is unchanged. Bottom, Representative images of tubulin immunocytochemistry in neurons fixed in MT buffer II. $\boldsymbol{B}$, Motor proteins implicated in the transport of DCVs and/or mitochondria display similar levels between control and $A \beta 0$-treated neurons. For immunocytochemistry, a minimum of 24 cells per condition from at least 3 different cultures were analyzed; for immunoblots, extracts from three different cultures were analyzed. ${ }^{*} p<0.05 ;{ }^{* *} p<0.005$, statistically significant differences from vehicle-treated neurons

ence of bundled MT arrays using semiquantitative immunocytochemistry. MT appearance between control and $\mathrm{A} \beta \mathrm{O}$ treated neurons (Fig. 3A) was indistinguishable $(n=25$ cells for both conditions).

Because degradation of synaptic proteins (e.g., PSD-95) results from $\mathrm{A} \beta \mathrm{O}$ exposure (Roselli et al., 2005), we asked whether the $\mathrm{A} \beta \mathrm{O}$-induced transport defect might be explained by degradation of elements of the transport apparatus. To answer this 
question, we measured protein levels of the motor protein dynein, the primary motor for retrograde transport, and of the anterograde kinesins, KIF1A, KIF5A, and KIF5C, motors implicated in the transport of DCVs and/or mitochondria (Hirokawa and Noda, 2008; Park et al., 2008), as well as total tubulin levels. Treatment with $\mathrm{A} \beta \mathrm{O}$ s for $18 \mathrm{~h}$ did not modify the total level of tubulin or any of the motor proteins investigated, eliminating the possibility that axonal transport defects could be caused by protein degradation (Fig. $3 B$ ). Together, these data indicate that the mechanism by which $\mathrm{A} \beta \mathrm{O}$ s disrupt transport is not related to MT destabilization or changes in protein levels directly required for organelle transport.

\section{Discussion}

$\mathrm{A} \beta \mathrm{O}$ s are central to the pathology of $\mathrm{AD}$ and lead to neuronal dysfunction, including dysregulation of NMDARs and blockade of LTP (Lambert et al., 1998; Wang et al., 2002; De Felice et al., 2007). This study demonstrates that $A \beta O$ s instigate disruption of axonal transport via a mechanism initiated by NMDARs and mediated by GSK- $3 \beta$. We further demonstrate that $\mathrm{A} \beta \mathrm{O}$ s do not cause major alterations in the structure of the microtubule network, suggesting that dysregulation of intracellular signaling cascades, not disintegration of microtubules, may negatively impact FAT. We focused our attention on the transport of mitochondria and BDNF-containing vesicles due to the important roles that mitochondria and BDNF play in neuronal health and survival, as well as in synaptic function and plasticity (Mattson et al., 2008; Greenberg et al., 2009). Because early memory loss in AD is increasingly recognized as a result of synapse failure, our current results suggest that, in addition to participating in mechanisms of axonopathy and neuronal degeneration, the transport defect induced by $\mathrm{A} \beta \mathrm{O}$ s also impacts the transport of organelles critical for plasticity.

Recent evidence indicates that $\mathrm{A} \beta \mathrm{O}$ s compromise synaptic transmission via dysregulation of NMDAR function (De Felice et al., 2007). Notably, synaptic modulation and changes in transport are linked (Schlager and Hoogenraad, 2009), and thus perturbing synaptic activity might have a direct effect on transport. Although the mechanism of action of $A \beta O$ s at the plasma membrane is not known specifically, $\mathrm{A} \beta \mathrm{O}$ s can modulate NMDA and insulin receptors (De Felice et al., 2007, 2009). To determine whether $\mathrm{A} \beta \mathrm{O}$-induced NMDAR dysfunction and transport impairment were mechanistically coupled, hippocampal neurons were treated with two NMDAR channel blockers and a competitive antagonist before $\mathrm{A} \beta \mathrm{O}$ treatment. D-AP5, a strong antagonist, completely prevented the disruption of transport induced by $\mathrm{A} \beta \mathrm{O}$. Interestingly, previous work from our group demonstrated that D-AP5 (but not memantine or MK-801) significantly reduced $\mathrm{A} \beta \mathrm{O}$ binding to hippocampal neurons (De Felice et al., 2007), likely explaining the prevention of transport defects in the current experiments. Understanding the exact role of NMDARs on disruption of FAT will require further investigation; however, one possibility is that $\mathrm{A} \beta \mathrm{O}$ s produce LTD-like stimuli via NMDARs by modulating signaling cascades that activate GSK-3 $\beta$ (Peineau et al., 2007), which in turn has deleterious effects on transport.

Alterations in intracellular calcium are another element coupling synaptic modulation via NMDARs and changes in transport. For example, $\mathrm{Ca}^{2+}$ is a regulator of mitochondrial transport via the $\mathrm{Ca}^{2+}$ responsive signaling protein Miro (Wang and Schwarz, 2009), and increases in cytosolic $\mathrm{Ca}^{2+}$ via synaptic activity lead to decreased mitochondrial transport. Conversely, transport of AMPA receptors and of recycling endosomes is dependent on increased neuronal $\mathrm{Ca}^{2+}$ levels (Wang et al., 2008). The role of $\mathrm{Ca}^{2+}$ on DCV transport has been investigated in Drosophila motor neurons, where a transient increase is required for the capture of transiting vesicles (Wong et al., 2009). However, the role of $\mathrm{Ca}^{2+}$ in long-range microtubule transport in neurons is not fully understood. For example, axonal transport in isolated squid axoplasm is unaffected by changes in $\mathrm{Ca}^{2+}$ levels (Brady et al., 1984). Although we cannot rule out a role for $\mathrm{Ca}^{2+}$ influx via NMDARs affecting DCV transport, the fact that $\mathrm{Ca}^{2+}$ alterations are not synchronous with the observed changes in transport suggests that they are not likely to play a significant role. In fact, the timeframe of intraneuronal $\mathrm{Ca}^{2+}$ changes induced by $\mathrm{A} \beta \mathrm{O}$ s is on the order of seconds to minutes (De Felice et al., 2007) whereas $\mathrm{A} \beta \mathrm{O}$-induced transport defects take several hours $(>4$ h) to develop. Additionally, several forms of delayed calciumtriggered events described thus far, such as glutamate-induced excitotoxicity, delayed cytoplasmic $\mathrm{Ca}^{2+}$ dysregulation, lead to neuronal death in $<2 \mathrm{~h}$ (Szydlowska and Tymianski, 2010), whereas our results demonstrate that neurons are not severely compromised for up to $18 \mathrm{~h}$ in the presence of $0.5 \mu \mathrm{M} \mathrm{A} \beta O$ s. Finally, neuronal death is not induced by $\mathrm{A} \beta \mathrm{O}$ s for up to $5 \mathrm{~d}$ at concentrations more than twice those used in the present study (Deshpande et al., 2006). Thus, it seems unlikely that $\mathrm{Ca}^{2+}$ dysregulation induced by aberrant NMDAR activation is a primary cause for the disruption of transport.

Another pathology induced by $\mathrm{A} \beta \mathrm{O}$ s is excessive generation of ROS (De Felice et al., 2007). Although ROS are thought to cause transport defects in neurodegenerative disorders (Morfini et al., 2009), a salient role for ROS in the present study is not supported by the finding that $N$-acetyl-cysteine, a potent cellpermeant antioxidant, had no protective effect against $\mathrm{A} \beta \mathrm{O}$ induced inhibition of transport under our experimental conditions (data not shown).

Dysregulation of signaling cascades that modulate FAT could be a contributing factor in $\mathrm{AD}$ (Morfini et al., 2009). GSK-3 $\beta$ is of particular interest, as it can be activated by fibrillar forms of $\mathrm{A} \beta$, and active GSK-3 $\beta$ is found in neurofibrillary tangles (NFTs) in postmortem AD brains (Giese, 2009). GSK-3 $\beta$ activation by fibrillar $\mathrm{A} \beta$ has been implicated in disruption of mitochondrial transport in primary neurons (Rui et al., 2006). In addition, in squid axoplasm activated GSK-3 $\beta$ selectively disrupts anterograde transport of organelles by uncoupling kinesin-I from its cargo (Morfini et al., 2002). Our results demonstrate that bidirectional transport in hippocampal neurons is disrupted by $\mathrm{A} \beta \mathrm{O}$ s. The impairment is higher for anterograde transport, with possible consequences in the distribution of organelles to distal portions of the cell, e.g., synapses. Although the motor for DCV transport has not been clearly identified in mammalian neurons, it appears likely that $\mathrm{A} \beta \mathrm{O}$ s preferentially disrupt a plus-end motor, possibly KIF1A (Park et al., 2008). Whether KIF1A is regulated by GSK- $3 \beta$ is yet to be determined. Interestingly, inhibition of bidirectional transport was prevented in cells treated with GSK-3 $\beta$ inhibitors. It is possible that GSK-3 $\beta$ largely governs anterograde transport (Morfini et al., 2002); however, several recent studies have uncovered regulatory mechanisms that are coordinated through opposing motors, whereby disrupting the action of one motor disrupts bidirectional transport (Ally et al., 2009). Our results suggest that GSK- $3 \beta$ is a central regulator of DCV trafficking and that this kinase may phosphorylate components of the transport complex directly or indirectly. 
$\mathrm{A} \beta \mathrm{O}$ s are known to induce hyperphosphorylation of tau (De Felice et al., 2008); however, it is unclear how this modification of tau influences transport. Destabilization of microtubules results from exposure to high concentrations (up to tenfold compared with this study) of both fibrillar and nonfibrillar $A \beta$ aggregates (Blurton-Jones and Laferla, 2006; King et al., 2006); however, no change in microtubule stability was observed in our experiments using $0.5 \mu \mathrm{M} \mathrm{A} \beta \mathrm{O}$. These results further support the notion that dysregulation of signaling cascades mediated by GSK- $3 \beta$ result in FAT defects.

One outstanding question is how the binding of $A \beta O$ s, thought to localize predominantly to dendritic synaptic sites (Klein, 2006), leads to an axonal transport deficit. We have observed a reduction in dendritic transport of DCVs in the presence of $\mathrm{A} \beta \mathrm{O}$ s (unpublished observations); however, we have yet to distinguish the temporal sequences of these events, i.e., to determine whether dendritic transport deficits precede axonal deficits. Nevertheless, the molecular constituents involved in regulation of transport, for example GSK-3 $\beta$, are present in both axonal and dendritic compartments (Peineau et al., 2008). It is also possible that GSK- $3 \beta$ is activated in dendrites and then either diffuses or is actively transported into the axon. Finally, we propose that $\mathrm{A} \beta \mathrm{O}-$ induced transport defects are a temporally intermediate insult faced by $\mathrm{AD}$ neurons, as has been suggested more generally for axonopathies (Morfini et al., 2009). Upon A $\beta O$ binding to neurons, events such as aberrant calcium influx and generation of ROS are immediate effects; on the other hand, the generation of NFTs and the resulting neurodegeneration are longer-term effects. Transport defects likely contribute to neuropathophysiology on many levels due to the centrality of transport to neuronal function.

\section{References}

Ally S, Larson AG, Barlan K, Rice SE, Gelfand VI (2009) Opposite-polarity motors activate one another to trigger cargo transport in live cells. J Cell Biol 187:1071-1082.

Black MM, Slaughter T, Moshiach S, Obrocka M, Fischer I (1996) Tau is enriched on dynamic microtubules in the distal region of growing axons. J Neurosci 16:3601-3619.

Blurton-Jones M, Laferla FM (2006) Pathways by which Abeta facilitates tau pathology. Curr Alzheimer Res 3:437-448.

Brady ST, Lasek RJ, Allen RD, Yin HL, Stossel TP (1984) Gelsolin inhibition of fast axonal transport indicates a requirement for actin microfilaments. Nature 310:56-58.

De Felice FG, Velasco PT, Lambert MP, Viola K, Fernandez SJ, Ferreira ST, Klein WL (2007) Abeta oligomers induce neuronal oxidative stress through an $N$-methyl-D-aspartate receptor-dependent mechanism that is blocked by the Alzheimer drug memantine. J Biol Chem 282:11590-11601.

De Felice FG, Wu D, Lambert MP, Fernandez SJ, Velasco PT, Lacor PN, Bigio EH, Jerecic J, Acton PJ, Shughrue PJ, Chen-Dodson E, Kinney GG, Klein WL (2008) Alzheimer's disease-type neuronal tau hyperphosphorylation induced by A beta oligomers. Neurobiol Aging 29:1334-1347.

De Felice FG, Vieira MN, Bomfim TR, Decker H, Velasco PT, Lambert MP, Viola KL, Zhao WQ, Ferreira ST, Klein WL (2009) Protection of synapses against Alzheimer's-linked toxins: insulin signaling prevents the pathogenic binding of Abeta oligomers. Proc Natl Acad Sci U S A 106:1971-1976.

Deshpande A, Mina E, Glabe C, Busciglio J (2006) Different conformations of amyloid beta induce neurotoxicity by distinct mechanisms in human cortical neurons. J Neurosci 26:6011-6018.

Ferreira ST, Vieira MN, De Felice FG (2007) Soluble protein oligomers as emerging toxins in Alzheimer's and other amyloid diseases. IUBMB Life 59:332-345.

Giese KP (2009) GSK-3: a key player in neurodegeneration and memory. IUBMB Life 61:516-521.
Greenberg ME, Xu B, Lu B, Hempstead BL (2009) New insights in the biology of BDNF synthesis and release: implications in CNS function. J Neurosci 29:12764-12767.

Hirokawa N, Noda Y (2008) Intracellular transport and kinesin superfamily proteins, KIFs: structure, function, and dynamics. Physiol Rev 88:10891118.

Hiruma H, Katakura T, Takahashi S, Ichikawa T, Kawakami T (2003) Glutamate and amyloid beta-protein rapidly inhibit fast axonal transport in cultured rat hippocampal neurons by different mechanisms. J Neurosci 23:8967-8977.

Hoshi M, Sato M, Matsumoto S, Noguchi A, Yasutake K, Yoshida N, Sato K (2003) Spherical aggregates of beta-amyloid (amylospheroid) show high neurotoxicity and activate tau protein kinase I/glycogen synthase kinase3beta. Proc Natl Acad Sci U S A 100:6370-6375.

Kaech S, Banker G (2006) Culturing hippocampal neurons. Nat Protoc 1:2406-2415.

Kempf M, Clement A, Faissner A, Lee G, Brandt R (1996) Tau binds to the distal axon early in development of polarity in a microtubule- and microfilament-dependent manner. J Neurosci 16:5583-5592.

King ME, Kan HM, Baas PW, Erisir A, Glabe CG, Bloom GS (2006) Taudependent microtubule disassembly initiated by prefibrillar betaamyloid. J Cell Biol 175:541-546.

Klein WL (2006) Synaptic targeting by Abeta oligomers (ADDLS) as a basis for memory loss in early Alzheimer's disease. Alzheimers Dement 2:43-55.

Kwinter DM, Lo K, Mafi P, Silverman MA (2009) Dynactin regulates bidirectional transport of dense-core vesicles in the axon and dendrites of cultured hippocampal neurons. Neuroscience 162:1001-1010.

Lambert MP, Barlow AK, Chromy BA, Edwards C, Freed R, Liosatos M, Morgan TE, Rozovsky I, Trommer B, Viola KL, Wals P, Zhang C, Finch CE, Krafft GA, Klein WL (1998) Diffusible, nonfibrillar ligands derived from Abeta1-42 are potent central nervous system neurotoxins. Proc Natl Acad Sci U S A 95:6448-6453.

Mattson MP, Gleichmann M, Cheng A (2008) Mitochondria in neuroplasticity and neurological disorders. Neuron 60:748-766.

Morfini GA, Burns M, Binder LI, Kanaan NM, LaPointe N, Bosco DA, Brown RH Jr, Brown H, Tiwari A, Hayward L, Edgar J, Nave KA, Garberrn J, Atagi Y, Song Y, Pigino G, Brady ST (2009) Axonal transport defects in neurodegenerative diseases. J Neurosci 29:12776-12786.

Morfini G, Szebenyi G, Elluru R, Ratner N, Brady ST (2002) Glycogen synthase kinase 3 phosphorylates kinesin light chains and negatively regulates kinesin-based motility. EMBO J 21:281-293.

Muresan V, Muresan Z (2009) Is abnormal axonal transport a cause, a contributing factor or a consequence of the neuronal pathology in Alzheimer's disease? Future Neurol 4:761-773.

Park JJ, Cawley NX, Loh YP (2008) A bi-directional carboxypeptidase E-driven transport mechanism controls BDNF vesicle homeostasis in hippocampal neurons. Mol Cell Neurosci 39:63-73.

Peineau S, Taghibiglou C, Bradley C, Wong TP, Liu L, Lu J, Lo E, Wu D, Saule E, Bouschet T, Matthews P, Isaac JT, Bortolotto ZA, Wang YT, Collingridge GL (2007) LTP inhibits LTD in the hippocampus via regulation of GSK3beta. Neuron 53:703-717.

Peineau S, Bradley C, Taghibiglou C, Doherty A, Bortolotto ZA, Wang YT, Collingridge GL (2008) The role of GSK-3 in synaptic plasticity. Br J Pharmacol 153 Suppl 1:S428-437.

Pigino G, Morfini G, Atagi Y, Deshpande A, Yu C, Jungbauer L, LaDu M, Busciglio J, Brady S (2009) Disruption of fast axonal transport is a pathogenic mechanism for intraneuronal amyloid beta. Proc Natl Acad Sci U S A 106:5907-5912.

Roselli F, Tirard M, Lu J, Hutzler P, Lamberti P, Livrea P, Morabito M, Almeida OF (2005) Soluble beta-amyloid1-40 induces NMDA-dependent degradation of postsynaptic density-95 at glutamatergic synapses. J Neurosci 25:11061-11070.

Rui Y, Li R, Liu Y, Zhu S, Yu X, Sheng Z, Xie Z (2006) Acute effect of beta amyloid on synchronized spontaneous $\mathrm{Ca}^{2+}$ oscillations in cultured hippocampal networks. Cell Biol Int 30:733-740.

Schlager MA, Hoogenraad CC (2009) Basic mechanisms for recognition and transport of synaptic cargos. Mol Brain 2:25.

Seo YH, Jung HJ, Shin HT, Kim YM, Yim H, Chung HY, Lim IK, Yoon G (2008) Enhanced glycogenesis is involved in cellular senescence via GSK3/GS modulation. Aging Cell 7:894-907. 
Stokin GB, Lillo C, Falzone TL, Brusch RG, Rockenstein E, Mount SL, Raman R, Davies P, Masliah E, Williams DS, Goldstein LS (2005) Axonopathy and transport deficits early in the pathogenesis of Alzheimer's disease. Science 307:1282-1288.

Szydlowska K, Tymianski M (2010) Calcium, ischemia and excitotoxicity. Cell Calcium 47:122-129.

Walsh DM, Klyubin I, Fadeeva JV, Cullen WK, Anwyl R, Wolfe MS, Rowan MJ, Selkoe DJ (2002) Naturally secreted oligomers of amyloid beta protein potently inhibit hippocampal long-term potentiation in vivo. Nature 416:535-539.

Wang HW, Pasternak JF, Kuo H, Ristic H, Lambert MP, Chromy B, Viola KL, Klein WL, Stine WB, Krafft GA, Trommer BL (2002) Soluble oligomers of beta amyloid (1-42) inhibit long-term potentiation but not long-term depression in rat dentate gyrus. Brain Res 924:133-140.

Wang X, Schwarz TL (2009) The mechanism of $\mathrm{Ca}^{2+}$-dependent regulation of kinesin-mediated mitochondrial motility. Cell 136: 163-174.

Wang Z, Edwards JG, Riley N, Provance DW Jr, Karcher R, Li XD, Davison IG, Ikebe M, Mercer JA, Kauer JA, Ehlers MD (2008) Myosin Vb mobilizes recycling endosomes and AMPA receptors for postsynaptic plasticity. Cell 135:535-548.

Wong MY, Shakiryanova D, Levitan ES (2009) Presynaptic ryanodine receptor-CamKII signaling is required for activity-dependent capture of transiting vesicles. J Mol Neurosci 37:146-150. 